\title{
Graves Oftalmopati Tanılı Olguların Yoğunluk Ayarlı ve Üçboyutlu Konformal Retro-Orbital Radyoterapi Planlarının Dozimetrik Olarak İncelenmesi
}

\author{
Duygu BOLAT, Sibel KAHRAMAN ÇETINTAŞ, Sema GÖZCÜ TUNÇ, Meral KURT, \\ Candan DEMİRÖZ ABAKAY, Oğuz AYDIN, Habibe ALTAŞ
}

Uludağ Üniversitesi Tıp Fakültesi, Radyasyon Onkolojisi Anabilim Dalı, Bursa.

\begin{abstract}
ÖZET
Graves oftalmopati (GO) tanılı olguların radyoterapi ile tedavisinde; karșılıklı lateral üç boyutlu konformal radyoterapi (3BKRT) ve yoğunluk ayarlı radyoterapi (YART) teknikleri kullanılarak hedef hacmin ve riskli organların aldığı dozların karşılaştırılması amaçlanmıştır. Çaıışmada; GO tanılı 15 hastaya fraksiyon dozu 2 Gy toplam doz 20 Gy olacak şekilde 3BKRT ve YART tekniği ile iki ayrı tedavi planı oluşturuldu. Planlanan hedef hacmin (PTV) ve riskli organların aldığı doz değerleri karşılaş̧ırıldı ve homojenite indeksi (HI), konformite indeksi (CI) değerleri hesaplanıp Monitor Unit (MU) değerlerine bakıldı. PTV’nin $\mathrm{D}_{95 \%}(\mathrm{p}=0,583)$ değerinde iki teknik arasında fark görülmedi; $\mathrm{D}_{98 \%}$ $(p<0,001)$ değerinde YART tekniğinin üstünlügü görüldü. Sonuç olarak; hastanın katarakt olmasına neden olabilecek dozlardan kaçınmak istendiğinden, kullanılan karşılıklı lateral açıdan dolayı 3BKRT tekniğinin daha düşük doz radyasyon aldığı söylenebilir.
\end{abstract}

Anahtar Kelimeler: Graves Oftalmopatisi. Orbita Radyoterapisi. Üç Boyutlu Konformal Radyoterapi. Yoğunluk Ayarlı Radyoterapi.

A Dosimetric Study of Intensity Modulated and Three Dimensional Conformal Retro-Orbital Radiotherapy

Plans of Graves Ophthalmopthy Diagnosed Patients

\begin{abstract}
In the treatment of Graves Ophthalmopthy (GO) with radiotherapy, we aimed to compare the doses of target volume and critical organs by using mutual lateral three dimensional conformal radiotherapy (3DCRT) and intensity modulated radiotherapy (IMRT) techniques. In this study, two separete treatment plans were develepod with 3DCRT radiotherapy and IMRT with a fraction dose of 2 Gy and the total doses of 20 Gy in 15 patients with GO diagnosis. The dose values of the planned target volume (PTV) and critical organs were compared and homogeneity index (HI), conformity index (CI) values were calculated and Monitor Unit (MU) values were eveluated. There was no difference between two techniques at $\mathrm{D}_{95 \%}(\mathrm{p}=0,583)$ of PTV; $\mathrm{D}_{98 \%}(\mathrm{p}<0,001)$ took advantege of in IMRT technique. As a result; it can be said that the 3DCRT technique used for the lateral angle of the patient wants to avoid the doses that cause cataract.
\end{abstract}

Key Words: Graves ophthalmopthy. Intensity Modulated Radiotherapy. Orbit Radiotherapy. Three Dimensional Conformal Radiotherapy.

GO (Graves Oftalmopati); tiroid bezini ilgilendiren, göz ve deri gibi pek çok sistemi etkileyen otoimmün bir hastalıktır. Graves hastalığının ekstratiroidal önemli tanı kriterlerinden biri olan GO, "Graves orbitopatisi, Tiroid ile ilişkili oftalmopati, Tiroid göz hastalığı, Endokrin orbitopati” olarak da isimlendirilmektedir ${ }^{1}$. İlk olarak; 1835 y1lında Graves, 1840 y1lında Basedow tarafından tarif edilmiştir ${ }^{2}$. Guatr, orbitopati ve dermopati klasik üçlüsü ile anılır. Bu semptomlar; hastalığın gelişimi ile birlikte veya tek başlarına ve bağım-

Geliş Tarihi: 25 Nisan 2018

Kabul Tarihi: 21 Haziran 2018

Yüksek Lisans Öğrencisi / Duygu BOLAT

Uludağ Üniversitesi Tıp Fakültesi

Radyasyon Onkolojisi Anabilim Dalı

Tel.: 05459178138

E-posta: duygubolat1992@gmail.com sız olarak ortaya çıkabilir'. Hastaların $\% 3$ ila \%5'inde şiddetli oftalmopati gelişir ve hastaların yaşam kalitesini önemli derecede düşürür ${ }^{4}$. Ortalama ortaya çıkma yaşı 45 'dir. Kadınlarda erkeklere göre daha fazla görülmektedir. Kadınlarda yaygınlık \%2,5, erkeklerde $\% 0,23$ 'dür ${ }^{5}$. Ancak klinik tablo erkeklerde daha şiddetli seyretmektedir. Yaşlanma ile hastalığın şiddeti artış göstermektedir ${ }^{6}$.

GO'lu hastaların \%3'ünde alttaki etken yine bir otoimmün hastalık olan Hashimoto tiroiditidir ${ }^{7}$. Diğer risk faktörleri uzun süreli kontrolsüz hipertiroidizm, radyoaktif iyot tedavisi, stres, tedavi öncesi triiyodotironin (T3) yüksekliği ve sigara kullanımıdır ${ }^{8}$. Sigara çok önemli ve önlenebilir bir risk faktörü olup GO riskini 7 kat arttırmaktadır ${ }^{9}$. Hastalığın derecesi kişiden kişiye farklıllk gösterebilir. İlk belirtiler; parlak görme ve göz açıklığının artmasıdır. Bunun sebebi göz kapaklarındaki kasılmadır. Daha sonra göz kapakları 
ve göz çevresinde ödem ortaya çıkmaktadır. Hastalığın bir basamak daha ağırında, gözlerin öne itilmesi gerçekleşmektedir. İleri evrelerinde çift görme, görme alanında daralma, göz tansiyonu gibi sorunlara sebep olabilecektir ${ }^{10}$. Altta yatan patogenezin; aşırı lenfosit infiltrasyonu ve aşırı hidrofilik glikozaminoglikanlar üretimi ile birlikte, retrobulber alanda yağ ve bağ dokusu artışı, ekstraokuler kaslarda genişleme olduğuna inanılmaktadır. Tedavi seçeneği olarak; ağız yolu ile alınan kortikosteroid tedavisi, non-steroid antiinflamatuar, pentoksifilin, orbital radyasyon tedavisi ve nadir olarak cerrahi yöntemler uygulanabilir ${ }^{11}$.

Geçmişten günümüze geliştirilen 3BKRT (Üç Boyutlu Konformal Radyoterapi) ve YART (Yoğunluk Ayarlı Radyoterapi) gibi ileri radyoterapi teknikleri iyonize radyasyon kullanarak malign ve benign tümörlerin tedavisinde, tümöre istenilen dozu verirken, sağlıklı dokuların minimum doz almasını sağlar. Bu gibi teknikler sayesinde benign tümör olan GO hastalığ1, sağlıklı dokuları koruyarak radyoterapi ile tedavi edilir. GO gibi benign olan hastalıklarda radyoterapi, 35 yaşın üzerindeki hastalarda ikincil malignite nedeniyle, ötiroid durumunda ve kısa semptom süresiyle birlikte kullanılmalıdır (12-15). Radyoterapinin tek başına tedavi etkinliği \%60'dır ${ }^{16,17}$. Radyoterapi ile birlikte uygulanan steroid tedavisinin GO hastaları için en etkin tedavi yöntemi olduğu belirtilir ${ }^{18}$. Geleneksel olarak GO radyoterapisinde 1şınlama dozu 10 fraksiyonda 20 Gray (Gy)'dir ${ }^{19-22}$. Ancak; randomize bir çalışma 10 Gy'lik bir dozun da önemli tedavi sonuçları sağlayabildiğini gösterdi ${ }^{23}$. Düşük doz radyoterapinin, GO şiddetini kalıcı sonuçlarla ve minimal morbidite ile azaltmada etkili olduğu gösterilmiştir ${ }^{24-27}$.

3BKRT tedavi planlama tekniği; üç boyutlu görüntüleme sisteminde tanımlanan tümör hacmini yok eder ve böylece iki boyutlu doz planlama sistemini üç boyutlu tedavi planlaması ile değiştirir. 3BKRT tedavi planları; uygun bir plan elde edilene kadar gantri aç1sını ve kuvvet kombinasyonlarını (weight point, MU, vs.) geliştirdiği "ileri planlama" adlı bir teknik kullanılarak oluşturulur. Işın diyaframı, koruma bloklarıyla veya çok yapraklı kolimatör (ÇYK) kullanılarak modifiye edilebilir. YART; radyasyon alanlarını kullanan gelişmiş bir 3BKRT formu olmasına rağmen, YART kullanımında tedavi planlarının geliştirildiği yöntemde önemli bir fark vardır. YART; tedavi planlama yazılımının doz kısıtlamaları ile öngörülen dozu tümör hacmine ulaştırırken, aynı anda dozu normal dokularla sınırlandırdığı "ters planlama" özelliğiyle karakterize$\operatorname{dir}^{28}$.

$\mathrm{Bu}$ çalışmada GO tanılı 15 hastanın bilgisayarlı tomografi (BT) görüntüleri üzerine yapılan; olabildiğince sağlıklı dokuları koruyup, hedef hacmin en az \%98'inin reçete edilen dozun en az \%95'ini alacak şekilde iki farklı tedavi planlama tekniği oluşturulmuş ve sanal planlar dozimetrik olarak karşılaştırılmıştır.

\section{Gereç ve Yöntem}

\section{Hasta Seçimi ve Görüntülerinin Elde Edilmesi}

Bu çalışmada; Uludağ Üniversitesi Tıp Fakültesi Hastanesi Radyasyon Onkolojisi kliniğinde 2013 ve 2017 yılları arasında tedavi görmüş 15 GO tanılı hasta, Uludağ Üniversitesi Etik Kurulu'ndan alınan 11 Ocak 2018 tarihli 2018-1/30 nolu karar onayı ile seçildi. Kadın hastaların ortalama yaşı $55^{64-48}$ olmakla birlikte erkek hastaların ortalama yaşı $46^{63-30}$ olarak bulunmuştur. Her hastaya özel termoplastik maske hazırlandı ve üç boyutlu rekonstrüksiyon kesit görüntüleri; Siemens Somatom Emotion Duo Bilgisayarlı Tomografi Simülatör Ünitesi kullanılarak 3 mm kesit kalınlığ1 ile alındı. Tedavi öncesi tüm hastalara gerekli bilgiler verilip, tedavi sırasında hareketsiz kalınması istenildi. Üç boyutlu rekonstrüksiyon kesit görüntüleri, dijital ortamda DICOM (Digital Imaging and Communications in Medicine) aracılığ1 ile Monaco 5.1 Tedavi Planlama Sistemi'ne tedavi planları oluşturulmak üzere gönderildi.

\section{Tedavi Planlaması}

DICOM aracılığı ile; Monaco 5.1 Tedavi Planlama Sistemi'ne gönderilen 15 GO tanılı hastanın, mevcut BT görüntüleri üzerine Radyasyon Onkoloğu tarafından RTOG (Radiation Therapy Oncology Group) protokollerine uygun GTV (Net tümör hacmi), CTV (Klinik tümör hacmi), PTV ve riskli organların (gözyaşı bezi, lens, göz küresi, beyin sapı, hipofiz, optik kiazm) konturlamaları yapıldı. Tüm hastalar için günlük fraksiyon dozu 2 Gy ve toplam doz 20 Gy olacak şekilde tedavi planları oluşturuldu. Tüm planlar için PTV'nin en az \%98'inin, reçete edilen dozun en az $\% 95$ 'ini alması istenmiştir.

\section{BKRT Tedavi Planlamast}

Monaco 5.1 Tedavi Planlama Sistemi ile, lens dozundan kaçabilme amaçlı $80^{\circ}-90^{\circ}$ ve $270^{\circ}-280^{\circ}$ karşılıklı lateral açılarıyla $6 \mathrm{MV}$ foton enerjisiyle, Collapsed Cone hesaplama algoritması kullanılarak tedavi planları oluşturuldu. Işınlama alan boyutları, asimetrik alanlar olarak açıldı. Işın yönleri ve ağırlıkları, manuel olarak hedef hacmin ve kritik organların konumuna göre verildi. Ağırlık olarak MU değerleri, karşılıklı lateral ışınlar için eşit olarak dağıtıldı.

\section{YART Tedavi Planlamast}

Planlanan hedef hacime bağlı olarak $0^{\circ}, 40^{\circ}, 80^{\circ}, 110^{\circ}$, $250^{\circ}, 280^{\circ}, 320^{\circ}$ açıları ile $6 \mathrm{MV}$ foton enerjisiyle, Monte Carlo hesaplama algoritması kullanılarak Monaco 5.1 Tedavi Planlama Sistemi'nde tedavi planları oluşturuldu. Minimum segment genişliği $1 \mathrm{~cm}$, plan başına maksimum segment 250 ve segment başına 4 MU olacak şekilde tedavi planları oluşturulmuştur (Şekil-1). 


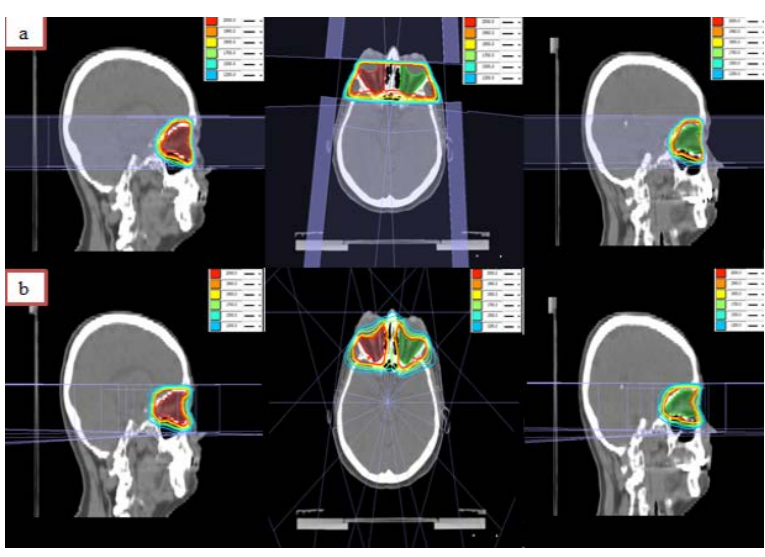

Şekil 1:

a) 3BKRT tedavi planının sağ ve sol orbita için sagital ve transvers görüntüleri b)YART tedavi planının sağ ve sol orbita için sagital ve transvers görüntüleri

\section{Homojenite İndeksi (HI)}

Homojenite indeksi; hedef hacimdeki doz dağılımının tek düzeliğini gösteren nesnel bir objedir. Literatürde verilen ICRU 83 (International Commission on Radiation Units and Measurements)'e göre homojenite indeksi şu şekilde tanımlanmıştır.

$$
\mathrm{HI}=\frac{D_{2 \%}-D_{98 \%}}{D_{50 \%}}
$$

$D_{2 \%}=$ Hedef hacmin \%2'sinin aldığ $\mathrm{doz}$

$D_{50 \% 6}=$ Hedef hacmin \%50'sinin aldığ $\mathrm{doz}$

$D_{98 \%}=$ Hedef hacmin \%98'inin aldığ $1 \mathrm{doz}$

HI'nın sıfıra yaklaşması planlan tedavi doz dağılımının oldukça homojen olduğunu gösterir. HI değeri sifirdan uzaklaştıkça doz homojenitesi azalmakta bu yüzden yapılan planın tercih edilme oranı azalmaktadır ve bu durumda yapılan plan tercihe göre tekrar gözden geçirilebilir ${ }^{29}$.

\section{Konformite İndeksi (CI)}

Konformite; tedavi uygunluğunu ifade eder. Tek baş1na yeterli bir bilgi vermez fakat plan kalite değerlendirilmesinde yardımc değerine eşit ise ideal tedavi planını temsil etmektedir. Eğer 0,9 ile 1 değeri aralığında ise; planlanan hacim istenilen doz değerinden az doz almasına rağmen kabul edilebilir sınırlar dahilindedir. 0.9 değerinden küçük ise; oluşturulan tedavi planı kabul edilebilir sinırlar dahilinde değildir. CI 1 değerinden büyük ise; planlanan hacim istenilen doz değerinden daha fazla doz değerini görmektedir ${ }^{30}$.

$\mathrm{CI}=\frac{T V_{R I} x T V_{R I}}{T V x V_{R I}}$

$T V_{R I}=$ Hedef hacim tarafindan kapsanan referans izodoz
$\mathrm{TV}=$ Hedef Hacim

$V_{R I}=$ Referans izodoz hacim

\section{İstatistiksel Analiz}

Çalışmadan elde edilen tüm veriler IBM Statistics Viewer Version 22 adli istatistiksel veri analiz programı ile analiz edildi. Veriler normal dağılıma uygun ise "Independent- Samples T Test" ve veriler normal dağılıma uygun değilse "Mann-Whitney U Test" uyguland. Veriler normal dağılıma uygun ise sonuçlar; "Ortalama \pm Standart Sapma" ve veriler normal dağılıma uygun değilse "Ortanca (Minimum-Maksimum)" olarak verildi. $\mathrm{p}<0,050$ istatistiksel olarak anlamlı kabul edildi.

\section{Bulgular}

PTV’nin $\mathrm{D}_{95 \%}(\mathrm{p}=0,583)$ değerinde iki tedavi tekniği arasında fark görülmemiştir; ancak $\mathrm{D}_{2 \%}(\mathrm{p}<0,001)$, $\mathrm{D}_{50 \%}(\mathrm{p}<0,001), \mathrm{D}_{98 \%}(\mathrm{p}<0,001), \mathrm{D}_{\min }(\mathrm{p}<0,001)$ değerlerinde YART tedavi tekniğinin üstünlüğü görülürken, $\mathrm{D}_{\max }(\mathrm{p}=0,001)$ değerinde $3 \mathrm{BKRT}$ tedavi tekniği daha üstün olarak bulunmuştur. PTV'nin HI $(\mathrm{p}<0,001)$ değeri için bakıldığında YART lehine anlamlı fark bulunurken; CI $(p<0,001)$ değeri için 3BKRT lehine anlamlı fark bulunmuştur. $\mathrm{MU}(\mathrm{p}<0,001)$ değeri açısından her iki teknik arasında anlamlı bir fark bulunurken; sonuçlar 3BKRT için $\mathrm{MU}_{\text {ort }}=252,00$ ve YART için $\mathrm{MU}_{\text {ort }}=643,15$ olarak bulunmuştur. Sağ gözyaş1 bezi için $\mathrm{D}_{2 \%} \quad(\mathrm{p}<0,001), \quad \mathrm{D}_{50 \%} \quad(\mathrm{p}<0,001), \quad \mathrm{D}_{\min }$ $(p=0,002)$ ve $D_{\max }(p<0,001)$ değerlerinde anlamlı fark bulunmakla beraber; tüm değerlerde YART tekniğinin daha üstün olduğu görülmüştür. Sol gözyaşı bezi için $\mathrm{D}_{2 \%}(\mathrm{p}<0,001), \mathrm{D}_{50 \%}(\mathrm{p}<0,001), \mathrm{D}_{\min }(\mathrm{p}<0,001)$ ve $\mathrm{D}_{\max }(\mathrm{p}<0,001)$ değerlerinde anlamlı fark bulunmakla beraber; tüm değerlerde YART tekniğinin daha üstün olduğu görülmüştür. Sağ ve sol lens için; $\mathrm{D}_{2 \%}$ $(p<0,001), D_{50 \%}(p<0,001), D_{\min }(p<0,001)$ ve $D_{\max }$ $(p<0,001)$ değerlerinde anlamlı fark bulunmakla beraber; tüm değerlerde 3BKRT tekniğinin daha üstün olduğu görülmüştür. Sağ ve sol göz küresi için $\mathrm{D}_{2 \%}$ $(p<0,001), D_{50 \%}(p<0,001)$ ve $D_{\max }(p<0,001)$ değerlerinde YART tekniği lehine anlamlı fark görülürken; $\mathrm{D}_{\min }(\mathrm{p}<0,001)$ değerinde 3BKRT lehine anlamlı fark bulunmuştur. Beyin sap1, hipofiz, optik kiazm gibi planlanan alana uzak yerleşimli riskli organlar için $\mathrm{D}_{2 \%}(\mathrm{p}<0,001), \mathrm{D}_{50 \%}(\mathrm{p}<0,001), \mathrm{D}_{\min }(\mathrm{p}<0,001)$ ve $\mathrm{D}_{\max }(\mathrm{p}<0,001)$ değerlerinde anlamlı fark bulunmakla beraber; 3BKRT tekniğinin diğer tekniğe göre üstün bir başarı sağladığı görülmüştür. 


\section{Bolat, ark.}

Tablo I. 3BKRT ve YART tekniklerinde PTV dozları Gy cinsinden olmak üzere, CI, HI ve MU için elde edilen istatistiksel veriler

\begin{tabular}{|c|c|c|c|}
\hline & 3BKRT & YART & p Değeri \\
\hline \multicolumn{4}{|l|}{ PTV } \\
\hline$D_{2 \%}$ & $21,95 \pm 0,02$ & $21,75 \pm 0,10$ & $p<0,001$ \\
\hline$D_{50 \%}$ & $21,25 \pm 0,10$ & $20,76 \pm 0,06$ & $p<0,001$ \\
\hline$D_{95 \%}$ & $19,83 \pm 0,19$ & $19,86 \pm 0,09$ & 0,583 \\
\hline$D_{98 \%}$ & $18,99(18,06-19,77)$ & $19,54(19,47-19,76)$ & $p<0,001$ \\
\hline$D_{\min }$ & $8,70 \pm 3,19$ & $16,16 \pm 0,89$ & $p<0,001$ \\
\hline$D_{\max }$ & $22,17 \pm 0,08$ & $22,37 \pm 0,18$ & 0,001 \\
\hline $\mathrm{Cl}$ & $1,008 \pm 0,019$ & $1,041 \pm 0,003$ & $p<0,001$ \\
\hline $\mathrm{HI}$ & $0,138(0,101-0,195)$ & $0,105(0,094-0,131)$ & $p<0,001$ \\
\hline MU & $252,00(248,00-259,00)$ & $\begin{array}{c}643,15(564,21- \\
921,35)\end{array}$ & $p<0,001$ \\
\hline
\end{tabular}

$\mathrm{D}_{2,50,95,98 \%}$ : \%2,50,95,98'lik hacmin Gy cinsinden aldığı doz değerleri

$\mathrm{D}_{\min }$ : Gy cinsinden minimum doz değeri

$\mathrm{D}_{\text {max }}$ : Gy cinsinden maksimum doz değeri

Tablo II. 3BKRT ve YART tekniklerinde lens, göz küresi ve gözyaşı bezi için Gy cinsinden elde edilen istatistiksel veriler

\begin{tabular}{|c|c|c|c|c|c|c|}
\hline & \multicolumn{3}{|c|}{ SAĞ } & \multicolumn{3}{|c|}{ SOL } \\
\hline & 3BKRT & YART & $\stackrel{p}{\text { Değeri }}$ & 3BKRT & YART & $p$ Değeri \\
\hline \multicolumn{7}{|l|}{ LENS } \\
\hline$D_{2 \%}$ & $4,2 \pm 1,2$ & $7,8 \pm 0,7$ & $p<0,001$ & $4,3 \pm 1,0$ & $7,6 \pm 1,3$ & $p<0,001$ \\
\hline$D_{50 \%}$ & $2,5 \pm 0,5$ & $5,6 \pm 0,5$ & $p<0,001$ & $2,4(2,0-3,2)$ & $5,2(4,2-7,0)$ & $p<0,001$ \\
\hline$D_{\min }$ & $1,7 \pm 0,2$ & $4,0 \pm 0,7$ & $p<0,001$ & $1,8 \pm 0,2$ & $3,8 \pm 0,6$ & $p<0,001$ \\
\hline$D_{\text {max }}$ & $4,3 \pm 1,2$ & $8,3 \pm 0,8$ & $p<0,001$ & $4,4 \pm 1,0$ & $8,1 \pm 1,5$ & $p<0,001$ \\
\hline \multicolumn{7}{|l|}{ GÖZ } \\
\hline$D_{2 \%}$ & $\begin{array}{c}21,9(21,8- \\
22,2)\end{array}$ & $\begin{array}{c}19,7(19,3- \\
20,8)\end{array}$ & $p<0,001$ & $22,0 \pm 0,1$ & $19,8 \pm 0,3$ & $p<0,001$ \\
\hline$D_{50 \%}$ & $19,1 \pm 1,3$ & $15,4 \pm 0,7$ & $p<0,001$ & $\begin{array}{c}19,5(17,7- \\
20,4)\end{array}$ & $15,4(12,9-17,1$ & $p<0,001$ \\
\hline$D_{\min }$ & $1,3 \pm 0,1$ & $3,3 \pm 0,7$ & $p<0,001$ & $1,3 \pm 0,1$ & $3,0 \pm 0,6$ & $p<0,001$ \\
\hline$D_{\text {max }}$ & \begin{tabular}{|c|}
$22,1(21,9-$ \\
$22,3)$
\end{tabular} & $\begin{array}{c}20,2(19,7- \\
21,9)\end{array}$ & $p<0,001$ & \begin{tabular}{|c|}
$22,1(21,9-$ \\
$22,3)$
\end{tabular} & $20,3(20,1-21,0)$ & $p<0,001$ \\
\hline \multicolumn{7}{|c|}{$\begin{array}{c}\text { GÖZYASSI } \\
\text { BEZI }\end{array}$} \\
\hline$D_{2 \%}$ & $21,3 \pm 0,5$ & $16,8 \pm 1,1$ & $p<0,001$ & $21,3 \pm 0,5$ & $17,0 \pm 1,2$ & $p<0,001$ \\
\hline$D_{50 \%}$ & $\begin{array}{c}19,0(17,9- \\
20,1)\end{array}$ & $\begin{array}{c}11,1(10,2- \\
13,9)\end{array}$ & $p<0,001$ & $18,7 \pm 0,9$ & $11,4 \pm 1,5$ & $p<0,001$ \\
\hline$D_{\min }$ & $9,6 \pm 3,7$ & $5,9 \pm 1,0$ & 0,002 & $9,3 \pm 2,6$ & $5,7 \pm 0,8$ & $p<0,001$ \\
\hline$D_{\max }$ & $21,4 \pm 0,5$ & $17,8 \pm 1,0$ & $p<0,001$ & $21,4 \pm 0,4$ & $17,9 \pm 1,2$ & $p<0,001$ \\
\hline
\end{tabular}

$\mathrm{D}_{2,50 \%}$ : \%2,50'lik hacmin Gy cinsinden aldığı doz değerleri

$\mathrm{D}_{\min }$ : Gy cinsinden minimum doz değeri

$\mathrm{D}_{\max }$ : Gy cinsinden maksimum doz değeri
Tablo III. 3BKRT ve YART tekniklerinde brain stem, hipofiz, optik kiazm için Gy cinsinden elde edilen istatistiksel veriler

\begin{tabular}{|c|c|c|c|}
\hline & 3BKRT & YART & p Değer \\
\hline \multicolumn{4}{|c|}{ BEYIN SAPI } \\
\hline$D_{2 \%}$ & $0,402 \pm 0,044$ & $7,066 \pm 0,864$ & $p<0,001$ \\
\hline$D_{50 \%}$ & $0,246 \pm 0,027$ & $2,885 \pm 1,106$ & $p<0,001$ \\
\hline$D_{\min }$ & $0,091 \pm 0,014$ & $0,416 \pm 0,059$ & $p<0,001$ \\
\hline$D_{\max }$ & $0,451 \pm 0,052$ & $8,216 \pm 1,068$ & $p<0,001$ \\
\hline \multicolumn{4}{|c|}{ HiPOFiz } \\
\hline$D_{2 \%}$ & $1,844(1,052-4,862)$ & $7,435(5,208-9,216)$ & $p<0,001$ \\
\hline$D_{50 \%}$ & $0,948 \pm 0,143$ & $5,772 \pm 0,961$ & $p<0,001$ \\
\hline$D_{\min }$ & $0,636 \pm 0,083$ & $4,315 \pm 0,828$ & $p<0,001$ \\
\hline$D_{\max }$ & $2,178(1,097-7,292)$ & $\begin{array}{c}8,139(5,610- \\
10,550)\end{array}$ & $p<0,001$ \\
\hline \multicolumn{4}{|c|}{ OPTIKK KIAZMA } \\
\hline$D_{2 \%}$ & $0,866(0,649-1,630)$ & $\begin{array}{c}9,410(7,407- \\
10,578)\end{array}$ & $p<0,001$ \\
\hline$D_{50 \%}$ & $0,502(0,451-0,909)$ & $7,350(5,878-8,967)$ & $p<0,001$ \\
\hline$D_{\min }$ & $0,332(0,286-0,614)$ & $5,236(3,125-6,122)$ & $p<0,001$ \\
\hline$D_{\max }$ & $0,919(0,701-1,906)$ & $\begin{array}{c}10,052(7,721- \\
10,992)\end{array}$ & $p<0,001$ \\
\hline
\end{tabular}

$\mathrm{D}_{2,50 \%}: \% 2,50$ 'lik hacmin Gy cinsinden aldığı doz değerleri $\mathrm{D}_{\min }$ : Gy cinsinden minimum doz değeri

$\mathrm{D}_{\max }$ : Gy cinsinden maksimum doz değeri

\section{Tartışma ve Sonuç}

GO tedavisinin amacı; oküler ağrıyı hafifletmek, diplopiyi azaltmak, görüşü korumak ve kozmetik görünümü iyileştirmektir. Hastalığın etkili olduğu tedavi yöntemi; radyoterapi ile birlikte uygulanan kortikosteroid kullanımıdır. En yaygın uygulanan radyoterapi dozu 10 fraksiyonda 20 Gy'lik dozdur. GO radyoterapisinde; karşl1ıklı lateral alanlar (LOF) tekniği, basit planlama tekniği ve tedavi süresinin kolaylığı açısından, Radyasyon Onkologları ve Medikal Fizikçiler tarafindan yillardır tercih edilmektedir. LOF'a göre daha iyi hedef kapsayan ve normal dokulara karş1 daha iyi doz sağlayabilen 3BKRT tekniği de ileriki yıllarda kullanılmaya başlanmıştır. Bununla beraber YART tedavi tekniği; 3BKRT'den önemli derecede üstün $\mathrm{HI}$ ve CI oluşturması nedeniyle GO radyoterapisinde kullanılmaya başlanmıştır. 3BKRT ve YART tekniği daha sonraları baş-boyun ve orbital tümörler için geçerli bir standart radyasyon tedavi tekniği olarak geniş çapta kabul görmüştür. Biz de bu çalışma ile GO tedavisinde kullanılan 3BKRT ve YART tekniklerini 15 hasta ile değerlendirip, yaptığımız sanal planlar ile iki tekniğin birbirlerine göre avantaj ve dezavantajlarını inceledik.

Kouloulias ve arkadaşları ${ }^{31} 2013$ yılında yaptıkları çalışmada; 3BKRT tedavi planlama tekniği ile radyoterapi gören 17 hasta ile, GO tedavisinde radyoterapinin etkinliği, akut ve geç toksisite etkisini değerlendirmişlerdir. Hastalara CTV, PTV, sağ ve sol göz, sağ ve sol lens, beyin gibi riskli organ konturlamaları 


\section{GO İçin Yart ve 3BKRT RT Planlarının İncelenmesi}

yapılıp Eclipse Tedavi Planlama Sistemi kullanılarak tedavi planlaması yapılmıştır. Doz aralığı; reçete edilen dozun \%95 ile \%107'si arasında tutulmuştur. Tüm hastalar radyoterapi ile beraber kortikosteroid almışlardır. Elde edilen sonuçlara bakıldığında; hiçbir hastada retinopati gelişmemiştir ancak bazı hastalarda katarakt ve kronik kseroftalmi bildirilmiştir. Sigara içenlerde tedaviye yanıtın, sigara içmeyenlere göre daha yavaş olduğu belirtilmiştir. Tedavi bitiminden 57 ay sonra, sigara içmeye devam eden beş hastada tekrarlayan belirti ve semptomlar gelişmiş, bunu cerrahi dekompresyon izlemiştir.

Li ve arkadaşları ${ }^{32}$; 2017 yılında 116 hasta üzerinde yaptığı çalışma ile 7 alan YART planlama tekniği kullanımının, GO hastalarını tedavi etmedeki etkinliğini ve klinik sonuçlar açısından başarısını incelediler. Olguların; başlangıçtaki hastalığının şiddeti, tedavi yanıtı, akut ve uzun dönem komplikasyon verilerini çalışmaya dahil ettiler. Tedavi planlaması için; PTV, sağ ve sol lens, sağ ve sol göz, sağ ve sol optik sinir, sağ ve sol gözyaşı bezi konturlamaları çizilmiştir. Katarakt oluşumunu engelleme amaçlı olarak lens dozu 7 Gy'in altında tutulmaya çalışılmıştır. Hastalar; lineer hızlandırıcıda $6 \mathrm{MV}$ foton enerjisi kullanılarak tedavi edilmiştir. Radyasyona bağlı retinopati ve ikincil kanser riski görmemişlerdir. Bununla beraber; katarakt oluşumu ve kronik kseroftalmi, uzun dönem komplikasyon olarak bulunmuş ve iyi yönetilmiştir. $\mathrm{Bu}$ çalışmadan elde ettikleri veriler 1şı̆̆ında; YART tedavi planlama tekniği kullanımının, tatmin edici bir sempton kontrolü ile nispeten hafif ve kabul edilebilir radyasyona bağlı komplikasyonlar sonucu GO hastalarının tedavisinde kullanılabileceğini göstermişlerdir.

Zygulska $^{33}$; 2008 yılında 121 hasta ile yaptığı çalışmada 3BKRT tedavi planlama tekniğini dozimetrik olarak incelemiştir. Hastalar; Ocak 2000 ile Aralık 2003 tarihleri arasında 6 MV'lik foton enerjisiyle LOF tekniğiyle tedavi edilmiştir. Radyoterapi; intravenöz steroid tedavisi ile birlikte gerçekleștirilmiştir. Planlanan tekniklerde sağ ve sol PTV doz değeri ayrı ayrı değerlendirilmiş; sağ ve sol lens, sağ ve sol göz doz değerlerinin $D_{\max }$ ve $D_{\text {mean }}$ değerleri karşılaştırılmıştır. Çalışmadan elde ettikleri bulgular sonucunda; sağ ve sol PTV planlanan dozun \%98'ini almıştır. Sol lens için $\mathrm{D}_{\text {mean }}$ değerinin $1,1 \mathrm{~Gy}$, sağ lens için $\mathrm{D}_{\text {mean }}$ değerinin 1,13 Gy olduğu ve her iki lensin başarılı bir şekilde korunduğu görülmüştür. Sol göz için $\mathrm{D}_{\text {mean }}$ değeri 9,98 Gy ve sağ göz için $\mathrm{D}_{\text {mean }}$ değeri 9,88 Gy olarak bulunmuştur. Zygulska ${ }^{34} 2010$ yılında aynı çalışmadan derlediği başka bir makalede GO tedavisinde radyoterapinin rolünü ve toksisitesini değerlendirmiştir. Çalışmada kadın hastalar, sigara içmeyenler ve diyabetik olmayanlar çoğunluktadır. Sonuçlar değerlendirildiğinde; intravenöz steroid ile radyoterapinin birlikte uygulanmasının sağ göz üzerinde herhangi iyileștirici bir etkisi bulunmamasına rağmen, sol gözde yağ dokusu azalması ve optik sinir ödemi azalması açısından bir miktar iyileşme sağlandığı görülmüştür. Hastaların 11'inde hafif ile orta derecede akut reaksiyon gelişmiştir. Tedavi tamamlandiktan sonra; 3 katarakt vakas1 görülmüştür ancak; bu sonuç fizyolojik yaşlanma sürecine bağlanmıştır. Kadın ve diyabetik olmayan hastaların kombine tedaviye olumlu yanıt verdiği gösterilmiştir. Zygulska'nın yaptığı çalışmada buldukları sağ ve sol lens için 3BKRT lehine olan sonuç bizim çalışmamızla uyumlu bulunmuştur. Sağ ve sol göz için sonuçlarımız YART lehine olmuştur ancak; Zygulska'nın sonuçlarından daha yüksek doz değeri görmüştür.

Lee ve arkadaşları ${ }^{35} ; 10$ hasta ile yaptıkları çalışmada; LOF, 6 alan 3BKRT ve 7 alan YART tedavi planlama tekniğini karşılaştırmışlardır. GTV, PTV doz değerleri ile sağ ve sol göz, sağ ve sol lens, sağ ve sol optik sinir, sağ ve sol gözyaşı bezi, optik kiazm gibi kritik organları incelemişlerdir. Bütün değerlerde $\mathrm{D}_{\min }, \mathrm{D}_{\max }$, $\mathrm{D}_{\text {mean }}$ (Ortalama doz değeri), $\mathrm{D}_{\text {median }}$ (Ortanca doz değeri), $\mathrm{D}_{05}$ (\%5'lik hacmin aldığı doz değeri), $\mathrm{D}_{01}$ (\%1'lik hacmin aldığı doz değeri) değerlerine bakıp; HI,CI ve MU değerlerini incelemişlerdir. LOF ve YART teknikleri arasında bir inceleme yaptıklarında; GTV ve PTV için $D_{\text {min }}$ değerinin her iki teknik için de YART lehine olduğunu ancak; $D_{\text {mean }}$ değeri için GTV'de LOF ve PTV'de YART tekniğinin üstün olduğunu görürlerken diğer değerlerde anlamlı fark bulmamışlardır. CI ve HI değerlerine baktıklarında; YART ve LOF teknikleri arasında en iyi sonucun YART lehine olduğunu ancak; MU değerlerine baktıklarında en iyi sonucun $\mathrm{MU}_{\text {ort }}=197$ ile LOF tekniğine ait olduğunu gözlemlemişlerdir. Kritik organlara baktıklarında; anlamlı fark görülen çoğu değerde LOF tekniğinin üstünlüğü görülürken; optik sinir için bu sonuç YART lehine dönmüştür. Lee ve arkadaşlarının yaptıkları çalışmadaki PTV, MU, HI için verdiği sonuç ile bizim çalışmamızın verdiği sonuç YART'ın üstünlüğü ile sonuçlanmakla beraber; CI için sonuçlarımız uyum sağlamamaktadır. Kritik organlara bakıldığında; sağ ve sol göz, sağ ve sol gözyaşı bezi, sağ ve sol optik sinir dişındaki organlar için bulunan sonuçlar, Lee ve arkadaşlarının sonuçları ile uyumludur.

Miguel ve arkadaşları ${ }^{36} ; 14$ hasta ile yaptıkları çalışmada; LOF, 3BKRT ve VMAT tedavi tekniklerini dozimetrik olarak karşılaştırmışlardır. Çalışmada; PTV doz değeri ile sağ ve sol göz, sağ ve sol lens, sağ ve sol optik sinir, optik kiazm, sağ ve sol retina, sağ ve sol gözyaşı bezi gibi riskli organların aldığı doz değerlerini incelemişlerdir. Bütün değerler için; $\mathrm{D}_{\min }, \mathrm{D}_{\max }$, $\mathrm{D}_{\text {mean }}, \mathrm{D}_{\text {median }}, \mathrm{D}_{05}, \mathrm{D}_{01}$ değerlerine bakıp; HI,CI ve MU değerlerini incelemişlerdir. LOF ve 3BKRT teknikleri arasında; PTV ve HI için anlamlı fark bulunmazken, CI için sonuçların 3BKRT lehine, MU için LOF lehine olduğunu gözlemlemişlerdir. Riskli organlar incelendiğinde; anlamlı fark görülen çoğu değerde LOF tekniğinin üstünlüğü görülürken, sağ ve sol gözyaşı bezi için sonuç 3BKRT lehine olmuştur. Çalışma 


\section{Bolat, ark.}

sonuçlarına bakıldığında; MU ve gözyaşı bezi haricindeki riskli organlar için bulunan sonuçlar ile bizim sonuçlarımız uyumlu olarak görülmektedir.

Önceki verilere göre; 5 yıl içinde $\% 5$ 'e kadar radyasyon retinopatisi yaratabilecek radyasyon dozunun 45 Gy olduğu tahmin edilmektedir. Bununla beraber; kseroftalmi için gözyaşı bezinin alabileceği maksimum dozu Parsons ve arkadaşları ${ }^{37} 40$ Gy olarak vermişlerdir. Bizim çalışmamızda; düşük doz radyasyon vererek tedavi ettiğimiz hastalarda radyasyon retinopatisi ve kseroftalmi izlenmedi. Bu çalışmanın dozimetrik değerlendirmesi yayınımızda incelendi. İkincil malignite bir başka önemli sorun olmakla birlikte GO için radyoterapi ölüm riski, geleneksel LOF tekniğine göre 1000 kişi başına $(\%$ 0,7) 7 vaka olarak görülmüştür $^{38}$. YART tekniği uygulanan hastalarda; normal dokuların aldığı doz azaltılabildiğinden, teorik riskin hasta popülasyonu için kabul edilebilir olduğu ve bu nedenle ikincil bir kanserin saptanmadığı söylenebilir.

Biz yaptığımız çalışmada 3BKRT tekniği ile 7 alan YART tekniğini karşılaştırdık. PTV için $\mathrm{D}_{2 \%}, \mathrm{D}_{50 \%}$, $D_{95 \%}, D_{98 \%}, D_{\min }$ ve $D_{\max }$ değerlerine baktık ve $D_{95 \%}$ değerinde anlamlı fark bulamazken; $D_{\max }$ değeri için 3BKRT tekniğinin, ancak diğer değerlerde YART tekniğinin üstün olduğunu gözlemledik. CI ve MU için 3BKRT tekniğinin, HI için YART tekniğinin üstün olduğunu gördük. Sağ ve sol lens, beyin sap1, hipofiz, optik kiazm gibi riskli organlar için tüm degerlerde en iyi sonucu büyük bir fark ile 3BKRT tekniği verdi. Sağ ve sol gözyaşı bezi için sonuçlarımız tüm değerler için YART lehinedir. Sağ ve sol göz için $\mathrm{D}_{\text {min }}$ değeri 3BKRT lehine olurken, diğer değerler için sonuç YART lehine olmuştur.

Sonuç olarak; GO radyoterapisinde lens, göz, gözyaşı bezi gibi tümöre yakın komşuluklu organların ve beyin sapı, hipofiz, optik kiazm gibi tümöre uzak komşuluklu organların fonksiyonel olarak korunabilmesi için planlanan tedavi tekniğinin ne olacağı Radyasyon Onkoloğu ve Medikal Fizikçi tarafindan belirlenmelidir. Özellikle hastanın katarakt olmasına neden olabilecek dozlardan kaçınmak isteniyorsa; bizim çalışmamızın sonuçları neticesinde, hastanın anatomik ve klinik özelliklerine göre 3BKRT tekniğinin daha düşük doz radyasyon aldığı söylenebilir. Yine tümöre uzak komşuluklu organların 3BKRT tekniğinde düşük doz radyasyon aldığı görülür. Ancak YART tekniğinin, tümöre istenilen dozu 3BKRT'den daha homojen verdiği görülmektedir. Bununla beraber; YART tekniğinde gözyaşı bezinin 3BKRT'den daha düşük radyasyon dozu aldığı ve dolayısıyla kseroftalmi açısından daha avantajlı olduğu görülmüştür.

\section{Kaynaklar}

1. Schotthoefer EO, Wallace DK. Strabismus associated with thyroid eye disease. Current opinion in ophthalmology 2007;18.5:361-365.
2. Dallow RL, Netland PA. Management of thyroid ophthalmopathy (Graves' disease). Principles and practice of ophthalmology: clinical practice. Philadelphia: WB Saunders 1994;190522

3. Vilar-González S, Lamas-Oliveria C, Fagúndez-Vargas MA et al. Thyroid orbitopathy, an overview with special attention to the role of radiotherapy. Endocrinología y Nutrición (English Edition) 2015;62.4:188-199.

4. San Miguel I, Arenas M, Carmona R et al. Review of the treatment of Graves' ophthalmopathy. The role of the new radiation techniques. Saudi Journal of Ophthalmology 2017.

5. Davies TF, Larsen PR. Thyrotoxicosis. In: Larsen PR, Kronenberg HM (eds). Williams Textbook of Endocrinology. 10th edition. Pennsylvania: Saunders, Elsevier Science; 2003. 374-421.

6. Perros P, Crombie AL, Matthews JNS, Kendall-Taylor P. Age and gender influence the severity of thyroid-associated ophthalmopathy: a study of 101 patients attending a combined thyroid-eye clinic. Clinical endocrinology 1993;38.4:367-372.

7. Hiromatsu Y, Eguchi H, Tani J, Kasaoka M, Teshima Y. Graves' ophthalmopathy: epidemiology and natural history. Internal Medicine 2014;53.5:353-360.

8. Manso PG, Furlanetto RP, Wolosker AMB et al. Prospective and controlled study of ophthalmopathy after radioiodine therapy for Graves' hyperthyroidism. Thyroid 1998; 8.1:49-52.

9. Prummel MF, Wiersinga WM. Smoking and risk of Graves' disease. Journal-American Medical Associatıon 1993;269:479479.

10. Bartalena L, Tanda ML. Graves' ophthalmopathy. New England Journal of Medicine 2009;360.10:994-1001.

11. Bahn RS. Graves' ophthalmopathy. New England Journal of Medicine 2010;362.8:726-738.

12. Mcdougall IR, Donaldson SS. Radiotherapy for Graves ophthalmopathy: Current Treatment Recommendations. In: The Radiation Therapy of Benign Diseases. Karger Publishers 2001;57-64.

13. Bartalena L, Marcocci C, Gorman CA, Wiersinga WM, Pinchera A. Orbital radiotherapy for Graves' ophthalmopathy: useful or useless? Safe or dangerous? Journal of endocrinological investigation 2003;26.1:5-16.

14. Kuhnt T, Müller AC, Janich M et al. Radiotherapy for Graves' ophthalmopathy. Klinische Monatsblatter fur Augenheilkunde 2004;221.11:915-921.

15. Bartalena L, Marcoccı C, Pinchera A. Treating severe Graves' ophthalmopathy. Bailliere's clinical endocrinology and metabolism 1997;11.3:521-536.

16. Prummel MF, Berghout A, Wiersinga WM et al. Randomised double-blind trial of prednisone versus radiotherapy in Graves' ophthalmopathy. The Lancet 1993;342.8877: 949-954.

17. Tsujino K, Hirota S, Hagiwara $M$ et al. Clinical outcomes of orbital irradiation combined with or without systemic high-dose or pulsed corticosteroids for Graves' ophthalmopathy. International Journal of Radiation Oncology Biology Physics 2000;48.3:857-864.

18. Bordón E, Henríquez-Hernández LA, Lara PC et al. Prediction of clinical toxicity in locally advanced head and neck cancer patients by radio-induced apoptosis in peripheral blood lymphocytes (PBLs). Radiation oncology 2010;5.1: 4.

19. Bartalena L, Pinchera A, Marcocci C. Management of Graves' ophthalmopathy: reality and perspectives. Endocrine Reviews 2000;21.2:168-199.

20. Jaulerry C. The role of radiotherapy in Graves' ophthalmopathy. Journal francais d'ophtalmologie 2004;27.7:825-827.

21. Kao SCS, Kendler DL, Nugent RA, Adler JS, Rootman J. Radiotherapy in the management of thyroid orbitopathy: computed tomography and clinical outcomes. Archives of Ophthalmology 1993;111.6:819-823. 


\section{GO İçin Yart ve 3BKRT RT Planlarının İncelenmesi}

22. Perez CA, Brady LW, Halperin EC, Schmidt-Ulrich RK. Principles and practice of radiation oncology. Radiation treatment of benign disease 2004:2333-4.

23. Kahaly GJ, Rösler HP, Pitz S, Hommel G. Low-versus highdose radiotherapy for Graves’ ophthalmopathy: a randomized, single blind trial. The Journal of Clinical Endocrinology \& Metabolism 2000;85.1:102-108.

24. Gripp S, Doeker R, Glag M, Vogelsang P, Pape H. Conventional and virtual simulation in retrobulbar irradiation. Strahlentherapie und Onkologie: Organ der Deutschen Rontgengesellschaft...[et al] 2000;176.3:131-134.

25. Lacka K, Manuszewska E, Korczowska I, Lacki JK. The effect of methylprednisolone pulse treatment on cytokine network in Graves ophthalmopathy. Current eye research 2007;32.3:291297.

26. Marquez SD, Lum BL, Mcdougall IR, Katkuri S et al. Longterm results of irradiation for patients with progressive Graves'ophthalmopathy. International Journal of Radiation Oncology Biology Physics 2001;51.3:766-774.

27. Wakelkamp IMMJ, Tan H, Saeed P et al. Orbital irradiation for Graves' ophthalmopathy: Is it safe? A long-term follow-up study. Ophthalmology 2004;111.8:1557-1562.

28. Gupta T, Agarwal J, Jain S et al. Three-dimensional conforma radiotherapy (3D-CRT) versus intensity modulated radiation therapy (IMRT) in squamous cell carcinoma of the head and neck: a randomized controlled trial. Radiotherapy and Oncology 2012;104.3:343-348.

29. Yoon M, Park SY, Shin D et al. A new homogeneity index based on statistical analysis of the dose-volume histogram. Journal of applied clinical medical physics 2007;8.2:9-17.

30. Feuvret L, Noël G, Mazeron J-J, Bey P. Conformity index: a review. International Journal of Radiation Oncology Biology Physics 2006;64.2:333-342.
31. Kouloulıas V, Kouvaris J, Zygogianni A et al. Efficacy and toxicity of radiotherapy for Graves' ophthalmopathy: the University of Athens experience. Head Neck Oncol 2013;5.2:12.

32. Li Y-J, Luo Y, He W-M, Li P, Wang F. Clinical outcomes of graves' ophthalmopathy treated with intensity modulated radiation therapy. Radiation Oncology 2017;12.1:171.

33. Zygulska AL, Kowalska B. Irradiation of malignant exophthalmos in the course of Graves Basedow disease. Reports of Practical Oncology \& Radiotherapy 2008;13.4:187-195.

34. Zygulska A. Radiotherapy in the treatment of Graves ophthalmopathy-to do it or not?. Journal of ocular biology, diseases, and informatics 2010;3.1:1-11.

35. Lee VHF, Ng SCY, Choi CW et al. Comparative analysis of dosimetric parameters of three different radiation techniques for patients with Graves’ ophthalmopathy treated with retro-orbital irradiation. Radiation Oncology 2012;7.1:199.

36. San-Miguel I, Carmona R, Luque L et al. Volumetric Modulated Arc Therapy (VMAT) make a difference in retro-orbital irradiation treatment of patients with bilateral Graves' ophthalmopathy. Comparative analysis of dosimetric parameters from different radiation techniques. Reports of Practical Oncology \& Radiotherapy 2016;21.5:435-440.

37. Parsons JT, Bova FJ, Mendelhall WM et al. Response of the normal eye to high dose radiotherapy. Oncology (Williston Park, NY) 1996;10.6:837-47; discussion 847-8,851-2.

38. Takeda A, Shigematsu N, Suzuki S et al. Late retinal complications of radiation therapy for nasal and paranasal malignancies: relationship between irradiated-dose area and severity. International Journal of Radiation Oncology Biology Physics 1999;44.3:599-605. 
